\title{
A protocol for the inhospital emergency drug management of convulsive status epilepticus in adults
}

\author{
Shelley Jones, ${ }^{1}$ Clemens Pahl, ${ }^{2}$ Eugen Trinka, ${ }^{3}$ Lina Nashef ${ }^{4}$
}

The protocol is free to download online. Please visit the journal online (http://dx.doi.org/ 10.1136/practneurol-2013000712)

${ }^{1}$ Pharmacy Department, Kings College Hospital NHS

Foundation Trust, London, UK ${ }^{2}$ Department of Neuroscience Intensive Care, Kings College Hospital NHS Foundation Trust, London, UK

${ }^{3}$ Department of Neurology, Paracelsus Medical University, Salzburg, Austria

${ }^{4}$ Department of Neurology, Kings College Hospital NHS Foundation Trust, London, UK

\section{Correspondence to}

Shelley Jones, Clinical Pharmacy Teamleader, Neurosciences, Pharmacy Department, Kings College Hospital NHS Foundation Trust, Denmark Hill, London SE5 9RS, UK; shelley.jones1@nhs.net

\section{CrossMark}

To cite: Jones S, Pahl C, Trinka $\mathrm{E}_{\text {, et al. Pract Neurol }}$ 2014;14:194-197.

\section{INTRODUCTION}

There are many options for treating convulsive status epilepticus but one thing is clear: success is closely associated with timely intervention and adherence to a treatment protocol. ${ }^{1}$ Delayed intervention leads to treatment resistance and refractory status. There is little evidence from randomised controlled trials, especially for agents used after benzodiazepines. $^{2}$ Therefore, for now, the choices are mostly based not on Class 1 evidence but on accumulated and published experience.

Management protocols are mandatory if patients with status epilepticus are to receive prompt and appropriate treatment. Yet many hospitals do not have these or do not review them regularly. This protocol is adapted from that of King's College Hospital, London, UK, and is in line with the European consensus workshop. ${ }^{2}$ We aim to provide sufficient detail to satisfy the treating physician's practical requirements, while keeping the protocol simple and easily accessible. It should be used with precalculated dose/weight charts.

The treatment pathway comprises first benzodiazepine (first line), then an intravenous antiepileptic agent (second line) followed by, where necessary, general anaesthesia (third line). The choice of benzodiazepine and the route used remains open to discussion. While intravenous lorazepam remains the first choice in hospital, it is not always available and intravenous access is not always possible. Furthermore, the choice of benzodiazepine and its route of administration need revising as new evidence emerges, particularly given the success of intramuscular midazolam in the prehospital setting. ${ }^{3}$
To allow for different circumstances, drug availability and access, we list several options for stage 1 treatment with benzodiazepines.

With regards to choice of intravenous antiepileptic drug in the second stage, the limited available evidence prevents us from categorically choosing one over another. We have, however, suggested an order of preference; this is influenced more by local availability and familiarity with use in the emergency department rather than evidence of superiority. The order should be reviewed as further evidence emerges. Irrespective of the drug chosen, we stress the importance of giving adequate loading doses. We have selected doses in the middle of the usual ranges, recognising that these may need to change with time. Where there is a clear response but not full control of seizures, in a stable patient, it may be appropriate to optimise the antiepileptic drug dose, as well as to consider another second stage agent. Otherwise, treatment should promptly move to the general anaesthesia stage. We have not listed lacosamide-available intravenously and occasionally used in status epilepticusamong the second-stage agents: this needs reassessing as more evidence emerges. It is uncertain whether the doses need capping, depending on weight. This need probably varies with different drugs and also depends on the doses per kg body weight used. There is limited information using loading doses above $2500 \mathrm{mg}$ for phenytoin, $4000 \mathrm{mg}$ for levetiracetam and $3000 \mathrm{mg}$ for valproate: we suggest that their doses should be capped-as is usual clinical practicethough we acknowledge the lack of clear evidence. 
This protocol will hopefully fulfil requirements for most cases of status epilepticus and readers are welcome to download and adapt it for local use along with the precalculated dose-weight charts. It does not address cases where seizures continue despite adequate and appropriate general anaesthesia (refractory status epilepticus), ${ }^{4}$ which need specialised input, with several other possible treatment options considered, including other antiepileptic drugs, ketamine, corticosteroids, magnesium, intravenous immunoglobulin, ketogenic diet, neurostimulation and, for lesional cases, surgery.

\section{See the next 2 pages for the Protocol.}

Contributors LN conceived the protocol, and LN and SJ initiated the protocol design and content. CP provided expert information regarding neuroanaesthetic management of status epilepticus. ET provided expert review and comments during protocol development. LN produced the introductory manuscript presented with the protocol after discussion with ET. All authors contributed to refinement of the protocol and manuscript and approved the final copy.
Competing interests None.

Provenance and peer review Commissioned; externally peer reviewed. This paper was reviewed by Aiden Neligan, London, UK and Eelco Wijdicks, Rochester, USA.

\section{REFERENCES}

1 Aranda A, Foucart G, Ducassé JL, et al. Generalized convulsive status epilepticus management in adults: a cohort study with evaluation of professional practice. Epilepsia 2010;51:2159-67.

2 Shorvon S, Baulac M, Cross H, et al. TaskForce on Status Epilepticus of the ILAE Commission for European Affairs. The drug treatment of status epilepticus in Europe: consensus document from a workshop at the first London Colloquium on Status Epilepticus. Epilepsia 2008;49:1277-85.

3 Silbergleit R, Durkalski V, Lowenstein D, et al.; NETT Investigators. Intramuscular versus intravenous therapy for prehospital status epilepticus. N Engl J Med 2012;366:591-600.

4 Shorvon S, Ferlisi M. The treatment of super-refractory status epilepticus: a critical review of available therapies and a clinical treatment protocol. Brain 2011;134(Pt 10):2802-18. 
In-Hospital Emergency Drug Management of Convulsive Status Epilepticus in Adults See page 2 for essential parallel general measures

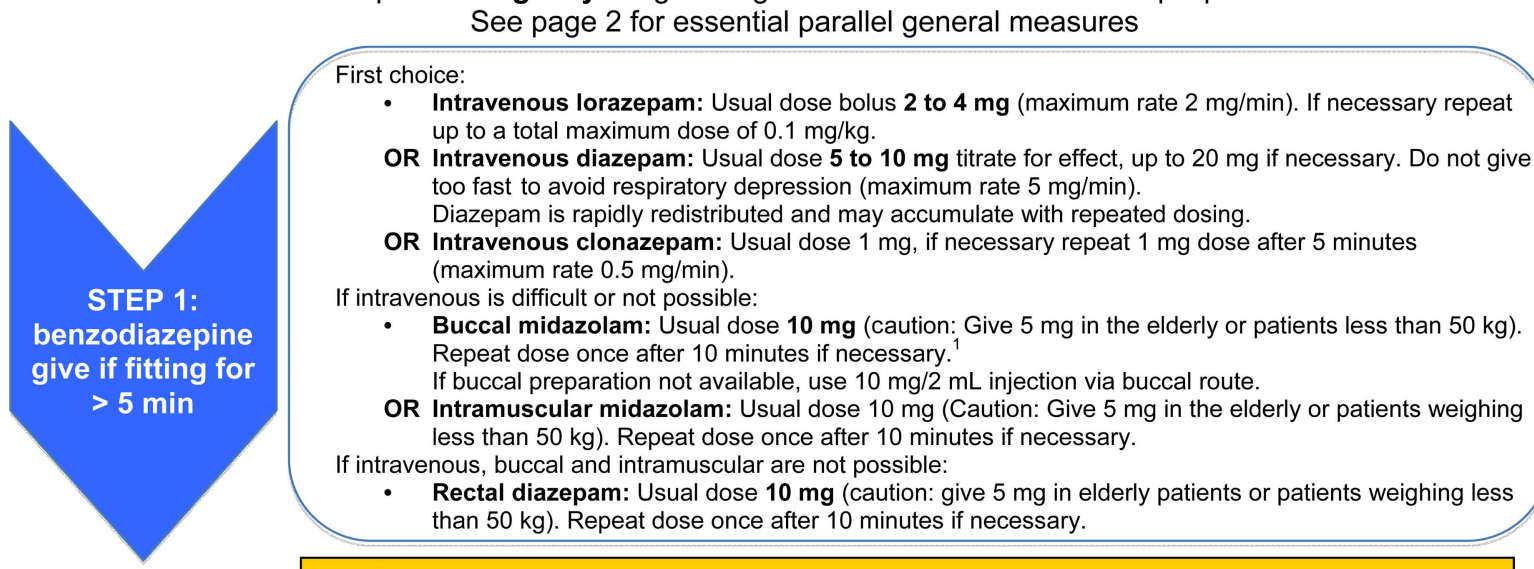

If seizures stop, the recurrence rate is high; most patients need an intravenous stage 2 antiepileptic drug (see below for doses) to prevent further seizures

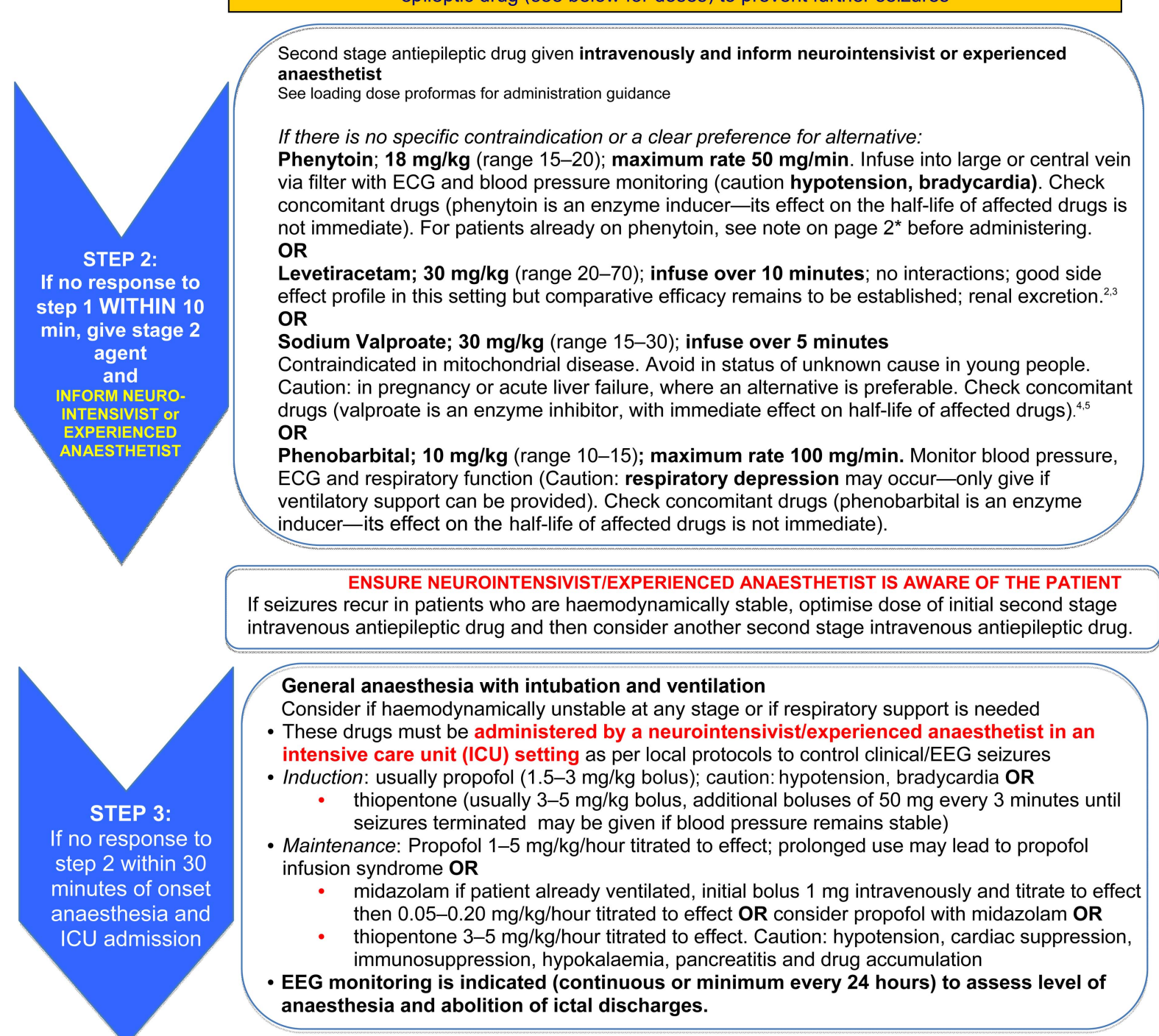

Over next 24-48 hours, optimise doses and levels of non-anaesthetic anti-epileptic drugs and, if no electrical or clinical evidence of ongoing seizures, withdraw anaesthesia to assess response. 


\section{General Management - In Parallel to Drug Management}

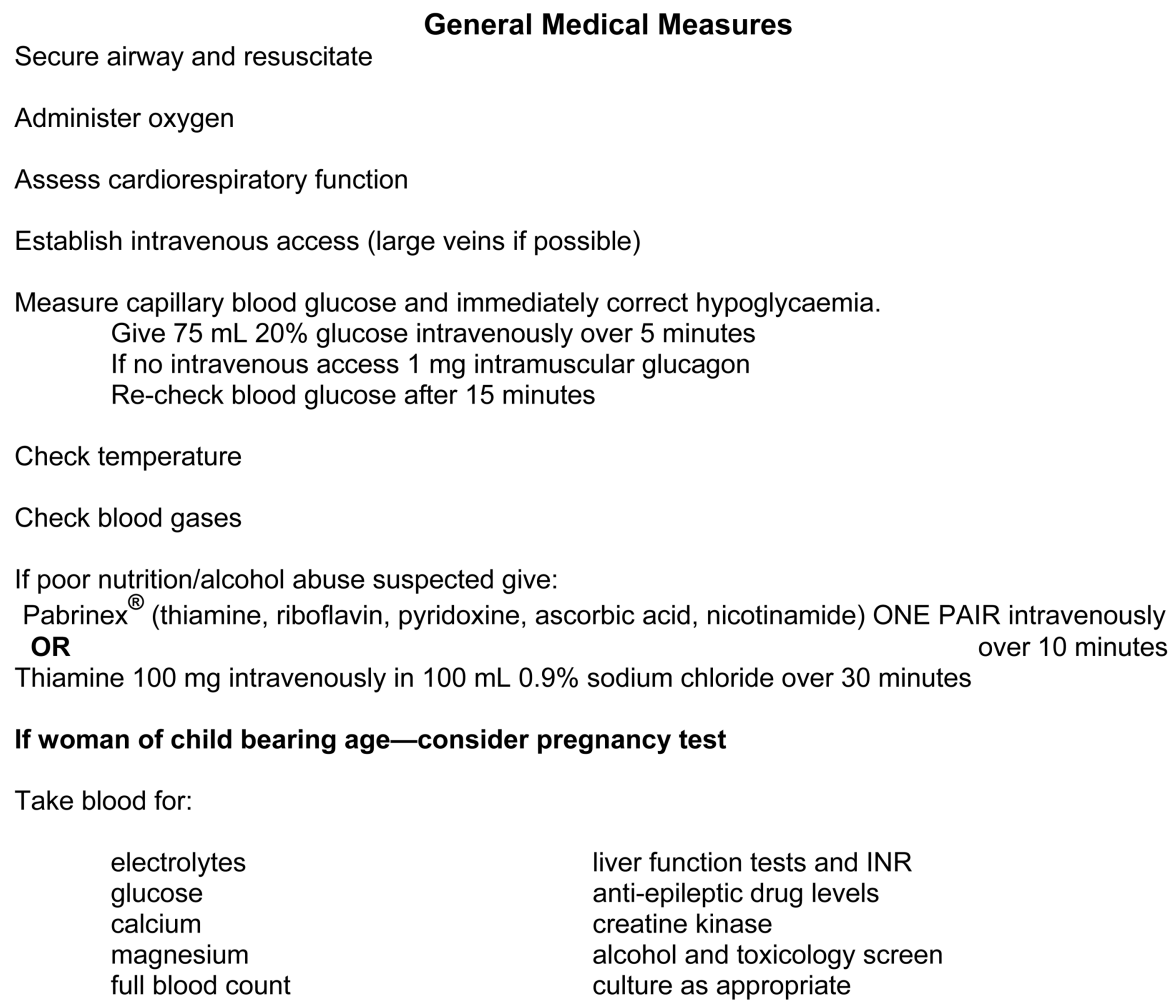

CAUTION: Not all seizures are epileptic

In psychogenic non-epileptic seizures 'pseudostatus' OR, treatment with sedation or anti-epileptic drugs is not indicated Consider urgent EEG and seek senior opinion

\section{Mandatory Seizure Related Measures}

- Investigate the cause of status and treat accordingly

- Consider reinstating any recently withdrawn anti-epileptic drug

- Continue existing anti-epileptic drugs

- Start maintenance anti-epileptic drug therapy promptly

- Refer to local specialist services

*For those on phenytoin, full loading is not appropriate but 'top-up' dose is given as per clinical decision or using the following formula:

DOSE $=($ target level $(\mathrm{mg} / \mathrm{L})-$ actual level obtained urgently $(\mathrm{mg} / \mathrm{L})) \times 0.7 \times$ weight in $\mathrm{kg}$

Example: If desired level is $20 \mathrm{mg} / \mathrm{L}$, actual level is $5 \mathrm{mg} / \mathrm{L}$ and weight is $70 \mathrm{~kg}$, then Dose $=20-5=15 ; 15 \times 0.7 \times 70=735 \mathrm{mg}$, rounded up to $750 \mathrm{mg}$

References:

1. Sibergleit R, Lowenstein D, Durbalski V, Conwit R and NETT investigations; RAMPART (Rapid Anticonvulsant Medication Prior to Arrival Trial); A doubleblind randomized trial of the efficacy of intramuscular midazolam versus intravenous lorazepam in the prehospital treatment of status epilepticus by paramedics; Epilepsia; 2011; 52 (Suppl 8); 45-7.

2. Uges JW, Huizen MD, Engelsman J, Wilms EB, Touw DJ, Peeters E, Vecht CJ; Safety and pharmacokinetics of intravenous levetiracetam as add-on in status epilepticus; Epilepsia; 2009; Mar; 50 (3); 415-21.

3. Navrarro V, Dagron C, De-meret S, An K, Baulac M, Carli P; Comparison of add-on levetiracetam versus placebo in a prehospital randomized trial in convulsive status epilepticus; Abstract at The $4^{\text {th }}$ London-Innsbruck Colloquium on status epilepticus and acute seizures; Salzburg 4-6 April 2013.

4. Misra UK, Kalita J, Patel R; Sodium valproate vs phenytoin in status epilepticus: a pilot study; Neurology; 2006; Jul 25; 67 (2); $340-2$.

5. Morton L, O'Hara KA, Coots BP, Pellock JM; Safety of Rapid Intravenous Valproate Infusion in Pediatric Patients; Paediatr Neurol; 2007; 36; 81-3. 